\title{
APLICAÇÃO DO MÉTODO DE FLUTUAÇÃo DE NÍVEL DA ÁGUA PARA A ESTIMATIVA DE RECARGA - EXEMPLO DO AQÜÍFERO RIO CLARO
}

\author{
APPLICATION OF WATER-TABLE FLUCTUATION METHOD TO ESTIMATE RECHARGE - \\ AN EXAMPLE OF RIO CLARO AQUIFER
}

Dagmar Carnier Neto ${ }^{1}$ e Chang Hung Kiang ${ }^{2}$

\begin{abstract}
RESUMO Durante quatro anos (2002 a 2005) de monitoramento de nível d'água em poços parcialmente penetrantes no Aqüífero Rio Claro, no município de Rio Claro - SP, foram obtidas séries temporais com variações de alta freqüência (período menor que 24h) e de baixa freqüência (período maior que 24h). Com isso, construiu-se uma hidrógrafa das variações sazonais, bastante similar a uma hidrógrafa típica de água superficial. O método WTF (water-table fluctuation) foi utilizado na estimativa da recarga anual e da variação do armazenamento em subsuperfície. Os resultados ressaltam a importância do aqüífero como reserva reguladora da água superficial na área estudada.
\end{abstract}

Palavras-chave: recarga, Aqüífero Rio Claro, flutuação de nível d'água

ABSTRACT Using water-level monitoring data obtained from four years period (2002 to 2005) in partially penetrating wells in Rio Claro Aquifer - Rio Claro city, São Paulo state - was possible to construct two time series, showing high frequency variations (less than $24 \mathrm{~h}$ period) and low frequency variations (more than $24 \mathrm{~h}$ period). The hydrograph from seasonal water level variations shows a very similar behavior compared to a surface water hydrograph. It's demonstrated the application of water-table fluctuation (WTF) method to estimate total annual recharge and variation of subsurface storage, with the results showing the importance of aquifer as regulating reserve to surface water of the study area.

Keywords: recharge, Rio Claro Aquifer, water-table fluctuation

\section{INTRODUÇÃO}

A demanda de recursos naturais para a produção de bens e manutenção da vida, não só no Brasil como em todo o mundo, cresce acompanhando o aumento da população. Neste contexto, a água, por sua importância para a sobrevivência, tem recebido atenção cada vez maior, sendo mesmo considerada como recurso estratégico para o futuro.

O monitoramento da água subterrânea constitui importante ferramenta de diagnóstico e controle das condições do aqǘf́ero, fornecendo informações que permitem saber o estado atual e as tendências dos parâmetros monitorados e registrando respostas de ações antrópicas e fatores naturais. O monitoramento do nível d'água, em particular, torna possível o acompanhamento contínuo e sistemático das variações no volume da água subterrânea, permitindo a gestão racional desse recurso.

A recarga da água subterrânea, por sua vez, é um fator dos mais importantes para sua gestão, pois tem relação direta com sua explotação, afetando inclusive o escoamento superficial. Lerner (1990) definiu conceitualmente três tipos de recarga, apresentadas a seguir:

- Recarga Direta - constitui a água adicionada à reserva subterrânea por meio de percolação vertical direta, atravessando a zona vadosa;

- Recarga Indireta - constitui a percolação de água para a zona saturada, através dos leitos de cursos de água superficial;

- Recarga Localizada - constitui a forma intermediária de recarga, resultante da concentração horizontal de água em superfície ou próximo dela, na ausência de canais bem definidos, como aquela acumulada em depressões após um evento de chuva.

Rushton(1997) faz também distinção entre recarga efetiva, que é aquela que realmente atinge o lençol freático, e recarga potencial, que incorpora toda a água infiltrada, sem necessariamente chegar ao aqüifero. As diferenças nas fontes de recarga, bem como os variados processos que a ocasionam, além de uma infinidade de fatores como clima, hidrologia e geologia implicam em uma variedade de métodos para sua estimação (VRIES e SIMMERS, 2002). 
No presente trabalho é demonstrada a aplicação do método WTF (water-tablefluctuation), baseado na flutuação do lençol freático, que tem sido usado em numerosos estudos de recarga (MEINZER, 1923; RASMUSSEN e ANDREASEN, 1959; GERHART 1986; HALL and RISSER, 1993), para estimativa da mesma em uma porção do Aqüífero Rio Claro, usando dados de monitoramento de nível d'água reunidos durante um período de quatro anos (2002-2005). Primeiramente é apresentada uma revisão geral sobre métodos de estimativa de recarga, seguida de uma descrição do sistema utilizado para obtenção dos dados de monitoramento. A análise dos dados é apresentada juntamente com a descrição dos fenômenos observados, passando-se para aplicação do método WTF na estimativa da recarga anual.

\section{MÉTODOS DE ESTIMATIVA DE RECARGA}

A finalidade do estudo da recarga é um fator decisivo na escolha da técnica a ser utilizada, dada sua implicação na escala espaço-temporal da estimativa a ser obtida. Exemplos típicos de estudos incluem a avaliação de reservas, com grande repercussão em estimativas sobre grandes áreas e escalas de tempo, e avaliação de vulnerabilidade à contaminação, que afeta áreas restritas e em curtos intervalos de tempo.

Scanlonetal.(2002), descrevemdetalhadamente vários métodos para estimativa de recarga e suas respectivas vantagens e desvantagens. Neste trabalho, as técnicas foram subdivididas de acordo com a zona hidrológica da origem dos dados, ou seja, água superficial, zona não-saturada e zona saturada; ainda, dentro de cada zona, as técnicas foram classificadas como métodos físicos, traçadores e modelagem numérica.

Dentre os métodos físicos, podem ser citados como exemplos a estimativa pela descarga do fluxo de base por meio da separação da hidrógrafa (água superficial), uso de lisímetros (em zona nãosaturada) e uso da flutuação do nível d'água (zona saturada).

A maior parte dos métodos físicos faz uso da equação do balanço hídrico, dada por:

$$
P+Q_{o n}=E T+Q_{o f f}+\Delta S
$$

onde $P$ é precipitação, $Q_{o n}$ e $Q_{o f f}$ são fluxos de água para dentro e para fora da área, ET é evapo-transpiração e $\Delta S$ é a variação no armazenamento.

Cada componente da equação pode ser separado em subcomponentes, de forma que os componentes do fluxo podem ser escritos como a soma do fluxo de água superficial, inter-fluxo e fluxo subterrâneo. A evapo-transpiração é separada de acordo com sua fonte (superficial, zona nãosaturada e zona saturada), e o armazenamento é dividido em porções que ficam retidas como água superficial (incluindo neve), na zona não-saturada e em reservatórios subterrâneos na zona saturada. Pode-se, então, reescrever a Equação (1) como (SCANLON et al., 2002):

$$
\begin{aligned}
& P+Q_{o n}^{s w}+Q_{o n}^{g w}=E T^{s w}+E T^{u z}+E T^{g w}+R_{0}+Q_{o f f}^{g w} \\
& +Q^{b f}+\Delta S^{s n o w}+\Delta S^{s w}+\Delta S^{1 z z}+\Delta S^{g w}
\end{aligned}
$$

onde os índices sobrescritos indicam a origem de cada componente ( $s w$ - água superficial, $g w-$ água subterrânea, $b f$ - fluxo de base, snow - água em forma de neve, $u z$ - zona não-saturada), $R_{0}$ representa o fluxo de água superficial para fora da área (runoff) e $Q^{b f}$ é fluxo de base (descarga em rios e córregos).

Segundo Schicht e Walton (1961), a recarga $R$ é tomada como qualquer infiltração de água que atinja a zona saturada, sendo escrita como:

$$
R=Q_{o f f}^{g w}-Q_{o n}^{g w}+Q^{b f}+E T^{g w}+\Delta S^{g w}
$$

onde $R$ é a recarga total, $\Delta S^{g w}$ é a mudança do armazenamento em subsuperfície (recarga líquida), $Q^{b f}$ é o fluxo de base, é a perda por evapotranspiração, e $Q_{o f f}^{g w}-Q_{o n}^{g w}$ é o valor líquido do fluxo em subsuperfície. Ou seja, toda água que chega ao nível d'água ou é perdida como fluxo subterrâneo, ou é descarregada para a superfície, ou é perdida por evapo-transpiração ou é retida no armazenamento.

A vantagem dos métodos que fazem uso da equação do balanço hídrico é sua flexibilidade. Não é necessário nenhum conhecimento $a$ priori sobre os mecanismos que controlam cada componente da equação, mas apenas seu valor final, possibilitando assim que esses métodos sejam aplicados sobre uma ampla gama de escalas, variando de centímetros e segundos até quilômetros e séculos. Por outro lado, uma das principais limitações relaciona-se às incertezas de medição de cada um dos componentes que, somadas, podem levar a desvios significativos no valor estimado da taxa de recarga.

Outra fonte de incerteza dos métodos físicos está associada ao valor da condutividade hidráulica (quando o método faz uso desse parâmetro, como no caso da estimativa pela Lei de Darcy), que pode variar muitas ordens de grandeza, em função das diferentes escalas dos dados utilizados (medições de laboratório versus medições em campo) e de sua variabilidade espacial. Essas incertezas são 
ainda maiores em sistemas não-saturados que nos saturados, devido às relações não-lineares entre condutividade hidráulica e quantidade de umidade no solo.

Os métodos baseados em traçadores, por sua vez, fazem uso de substâncias químicas de diversas origens, podendo ser do tipo aplicado (como o brometo e traçadores visuais), do tipo histórico (resultantes de atividade humana e eventos passados, como vazamentos de contaminantes ou testes nucleares atmosféricos, resultando em ${ }^{3} \mathrm{H}$ and ${ }^{36} \mathrm{Cl}$ ) e do tipo ambiental (com espécies que são produzidas naturalmente na atmosfera, como o $\mathrm{Cl}$ ). Pode-se também usar o calor como traçador em águas superficiais, embora seja um método cuja análise de dados é complexa e com soluções encontradas com uso de técnicas de inversão matemáticas que nem sempre apresentam soluções únicas (SCANLON et al., 2002).

Os traçadores são bastante úteis na estimativa da recarga efetiva sobre um longo período de tempo, mas não são capazes de fornecer séries temporais detalhadas sobre as variações da recarga. As fontes de incerteza desses métodos estão relacionadas a erros nas medidas de concentração das substâncias, nas estimativas de suas quantidades iniciais e nas premissas sobre os processos de transporte. Esses fatores podem se tornar um limitante na escolha do método. Por exemplo, o trítio resultante de testes com explosões nucleares presta-se melhor ao uso como traçador em áreas do hemisfério norte, posto que no hemisfério sul sua concentração chega a ser uma ordem de magnitude menor, gerando dificuldade na distinção entre o trítio natural, presente na chuva, e aquele produzido pela ação humana (SCANLON et al., 2002).

A modelagem numérica, que pode ser aplicada nas três classes referidas (água superficial e zonas saturada e não-saturada), desempenha um papel importante na estimativa da recarga, na medida em que é usada para avaliar os modelos conceituais, determinar sua sensibilidade em relação aos diversos parâmetros e predizer como futuras mudanças no clima e no uso da terra podem afetar as taxas de recarga.

O diagrama da Figura 1 mostra de forma esquemática a aplicação dos diversos métodos de estimativa de recarga, de acordo com o tamanho da área estudada e a escala temporal de estimativa.

Como todos os métodos possuem suas fontes de incertezas, é recomendável, sempre que possível, que diferentes técnicas sejam utilizadas de maneira complementar. Além disso, o processo de estimativa de recarga é, na maior parte das vezes, um processo iterativo, que vai sendo refinado à medida que novos dados são disponibilizados ao estudo.

\section{AQÜÍFERO RIO CLARO}

Segundo o Departamento de Águas e Energia Elétrica - DAEE (1981), o sistema Aqüífero Rio Claro consiste de um aqüífero livre pouco profundo, com vazões situadas entre $17 \mathrm{~m}^{3} / \mathrm{h}$ e $25 \mathrm{~m}^{3} / \mathrm{h}$, constituído por sedimentos pouco consolidados da Formação Rio Claro. Segundo Oliva (2002), o nível d'água subterrâneo do aqüífero Rio Claro está situado entre $2 \mathrm{~m}$ e $25 \mathrm{~m}$, prevalecendo os níveis com profundidades inferiores a $18 \mathrm{~m}$.

AFormaçãoRioClaro,porsuavez,écaracterizada por depósitos cenozóicos correspondentes a níveis escalonados na paisagem, vinculados a fases de aplainamento. Suas espessuras em geral são pequenas, não ultrapassando 30 metros (FREITAS et al., 1979). Estratigraficamente, a unidade encontra-se principalmente sobreposta à Formação Corumbataí. Na borda leste da Depressão Periférica, os sedimentos estão sobrepostos ao Subgrupo Itararé e à Formação Aquidauana e, em Vargem Grande do Sul - SP, aparece diretamente sobre o embasamento pré-cambriano (MELO, 1995). No município de Rio Claro, a espessura da formação varia consideravelmente, sendo mais espessa na região norte, onde encontra-se a Fazenda São José, e diminuindo gradativamente para sul (OLIVA, 2002).

Os dados obtidos por Oliva (2002), por meio da descrição de amostras de afloramentos e análise granulométrica, indicam que os arenitos da Formação Rio Claro possuem granulometria que varia de areia fina à média. Alguns deles apresentam alto teor de argilas, outros são conglomeráticos, indicando sedimentação em ambiente fluvial. 


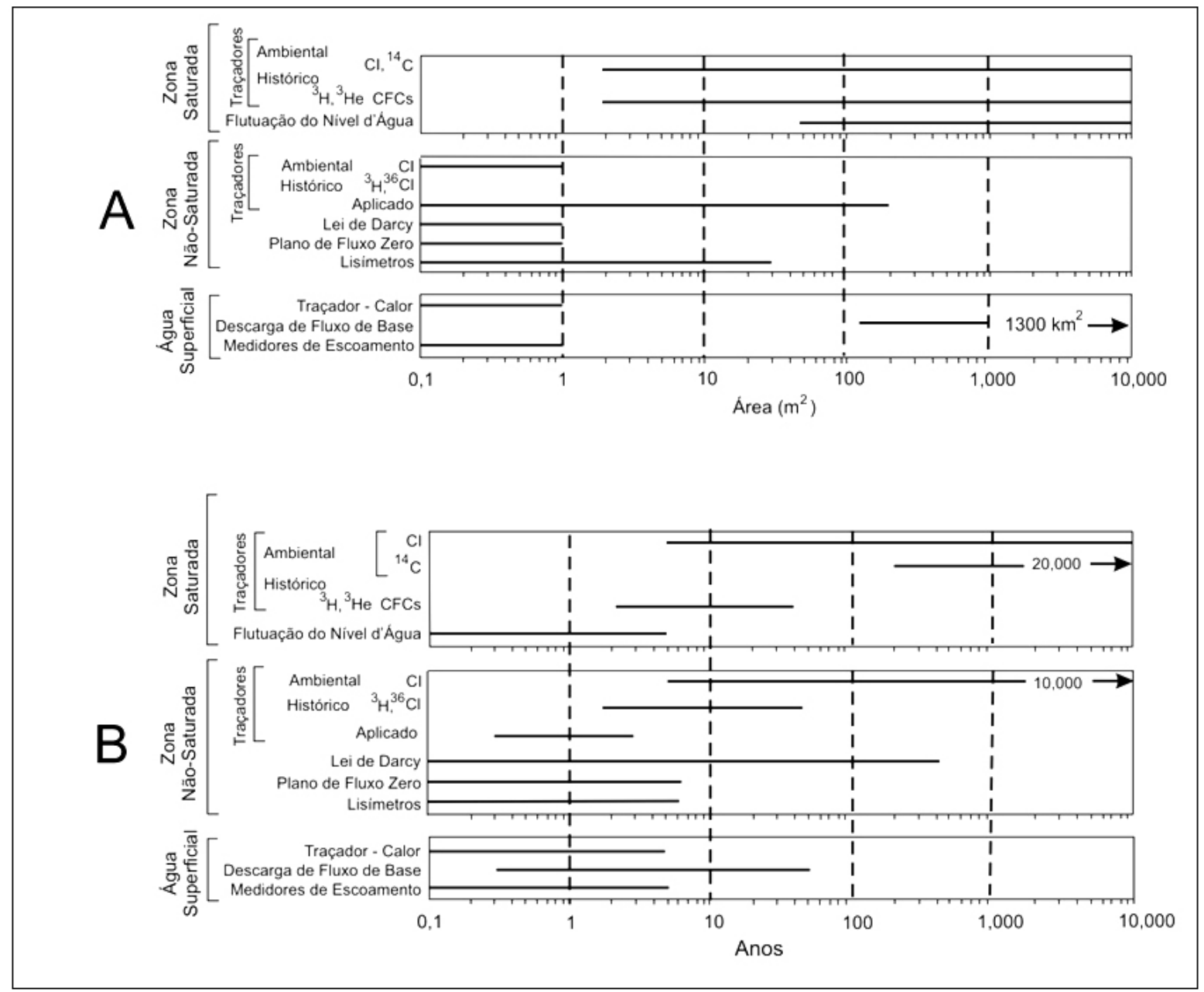

Figura 1 - Diagrama ilustrando a aplicação dos diversos métodos de estimativa da recarga de acordo com as escalas espacial e temporal (SCANLON et al, 2002). Em A, os métodos estão relacionados à dimensão da área de estudo; em $\mathrm{B}$, os métodos estão relacionados a diferentes escalas de tempo.

Figure 1 -Diagram illustrating the methods used to estimate recharge according to spatial and temporal scales (SCANLON et al, 2002). A emphasizes spatial scales. B emphasizes temporal scales.

A área de ocorrência da Formação Rio Claro é considerada globalmente como uma área de recarga do Aqüífero Rio Claro, onde as águas pluviais se infiltram no solo (recarga direta) e se deslocam em subsuperfície em direção aos cursos de águas superficiais, que constituem as descargas do aqüífero.

Estes locais de descarga situam-se geralmente próximos ao contato do Aqüífero Rio Claro com o aquitardo subjacente, constituído pela Formação Corumbataí, na área estudada.

\section{OBTENÇÃO DOS DADOS DE FLUTUAÇÃO DO NÍVEL D'ÁGUA}

Os poços cujos dados de monitoramento de nível d'água foram utilizados neste trabalho foram perfurados no Campus Bela Vista da Unesp, em Rio Claro - SP, penetrando parcialmente o Aqüífero Rio Claro. O primeiro poço monitorado foi o IGCE-3, construído em março de 2001, com profundidade de $17 \mathrm{~m}$. O poço foi revestido com tubo liso de PVC até 5,6m abaixo da superfície do terreno, sendo o restante do poço revestido com tubo ranhurado (filtro). O nível d'água, à época da perfuração, situava-se a $7,74 \mathrm{~m}$ de profundidade. Esse poço foi monitorado de abril de 2001 até abril de 2004, quando os equipamentos de monitoramento foram então transferidos para outro poço, IGCE-6, situado a cerca de $80 \mathrm{~m}$ do IGCE-3. Este novo poço foi perfurado em setembro de 2003, com as mesmas características construtivas, atingindo o aquitardo subjacente (Fm. Corumbataí) a $20,1 \mathrm{~m}$, coincidente com o final do poço. O início do filtro situa-se a $7,1 \mathrm{~m}$ de profundidade, com o NE situando-se a 9,8m após a perfuração.

A medição de nível d'água foi realizada de forma automatizada, utilizando-se um transdutor de pressão, com faixa de medição de 0 a $1,5 \mathrm{~m}$ de coluna d'água, com canículo para compensação barométrica, instalado de forma a permanecer 
submerso dentro do poço. $\mathrm{O}$ sinal elétrico proveniente do transdutor foi convertido para um valor digital, por meio de um medidor que possui uma interface padrão RS-232 para comunicação com computador. A acuracidade da sonda utilizada é de $0,1 \%$ do fundo de escala, o que corresponde a $1,5 \mathrm{~mm}$ para a função de medição escolhida. Para leitura do medidor e armazenamento dos dados foi utilizado o programa Wellplex (CHANG e CARNIER NETO, 2001). Este software foi desenvolvido no Laboratório de Hidrogeologia e Hidrogeoquímica (H2L) da Unesp de Rio Claro, com capacidade para automatizar o monitoramento de até oito instrumentos simultaneamente.

Neste trabalho, o Wellplex foi configurado para realizar uma aquisição a cada cinco segundos sendo que, semanalmente, o arquivo de monitoramento era fechado e um novo, iniciado. Essa rotina evitou a geração de arquivos muito grandes, ao mesmo tempo em que reduziu o risco de perda de dados por eventual falha no sistema.

\section{RESULTADOS DO MONITORAMENTO}

Para que os dados de nível d'água obtidos com o monitoramento pudessem ser interpretados, foi necessário um tratamento prévio das séries temporais brutas, composto por correções e filtragem (re-amostragem) .

O maior problema encontrado foi a perda de seqüências de dados (gaps) devido a falhas na instrumentação. Estimou-se que, da série de quatro anos completos, um total correspondendo a quase $20 \%$ da seqüência foi perdido. Para o preenchimento dos trechos com falhas, o método escolhido foi a interpolação linear, justificado pelo fato das seqüências perdidas serem, em sua maioria, de curta duração (de algumas horas até 3 dias), comparadas com a duração total da série (1460 dias), podendo assim serem aproximadas por uma reta. As duas maiores falhas contínuas, de 15 e 21 dias, ocorreram em trechos da série em que a tendência da curva era praticamente linear (durante a recarga de 2004 e no meio da recessão em 2003, respectivamente), o que também não gerou grande distorção no resultado final. Caso houvesse ocorrido alguma grande perda durante um trecho importante, como nas inflexões de máximo e mínimo, ainda assim seria possível obter uma aproximação, observando-se o comportamento da curva nos anos anteriores ou posteriores e fazendose um ajuste, por meio de interpolação polinomial ou curva de Bézier.
Outro tipo de correção necessária foi aquela referente a deslocamentos abruptos no valor medido, gerados pelo reposicionamento da sonda dentro do poço, visando mantê-la sempre submersa e dentro de sua faixa de medição, acompanhando as variações sazonais do nível d'água. Esses deslocamentos, também chamados de offsets, são corrigidos pela soma ou subtração de um valor constante para todos os pontos da série temporal, a partir daquele em que ocorre o deslocamento. Esse valor de correção é facilmente calculado, tomando-se a diferença entre a última medição ocorrida imediatamente antes do offset e a primeira imediatamente depois. Depois de corrigida, a série temporal completa, mostrada nesse trabalho, tem como referência um datum arbitrário posicionado a $633 \mathrm{~m}$ de altitude, cerca de $12 \mathrm{~m}$ abaixo da elevação local de $645 \mathrm{~m}$.

Por fim, com o intervalo de amostragem do sistema automatizado ajustado em cinco segundos, foram gerados cerca de vinte milhões de amostras (já descontada a porcentagem de dados perdidos) durante os quatro anos de monitoramento. Assim, foi necessário diminuir a quantidade de amostras da série temporal bruta, de forma a torná-la mais facilmente manipulável, de acordo com a freqüência dos fenômenos que se desejava analisar. Após a filtragem, foram geradas duas séries: uma com intervalo de aquisição de cinco minutos, para estudo das oscilações do nível d'água de alta freqüência, e outra com intervalo de 24 horas, para estudo das variações de baixa freqüência.

\section{OSCILAÇÕES DE ALTA FREQÜÊNCIA - EFEITO DA MARÉ TERRESTRE}

Embora o efeito das marés seja muito mais evidente sobre a massa líquida da Terra, as forças de tensão geradas pelos campos gravitacionais causam deformações também na massa sólida, causando a Maré Terrestre. Seu efeito sobre o nível d'água de poços em aqüíferos confinados é bem conhecido e documentado. Segundo Bredehoeft (1967), desde o final do século XIX existem observações a respeito das flutuações de nível causadas por esse fenômeno, e Robinson (1939) apud Todd (1959) descreve as variações de nível d'água de poços em Iowa e Novo México (EUA) associadas a marés. 


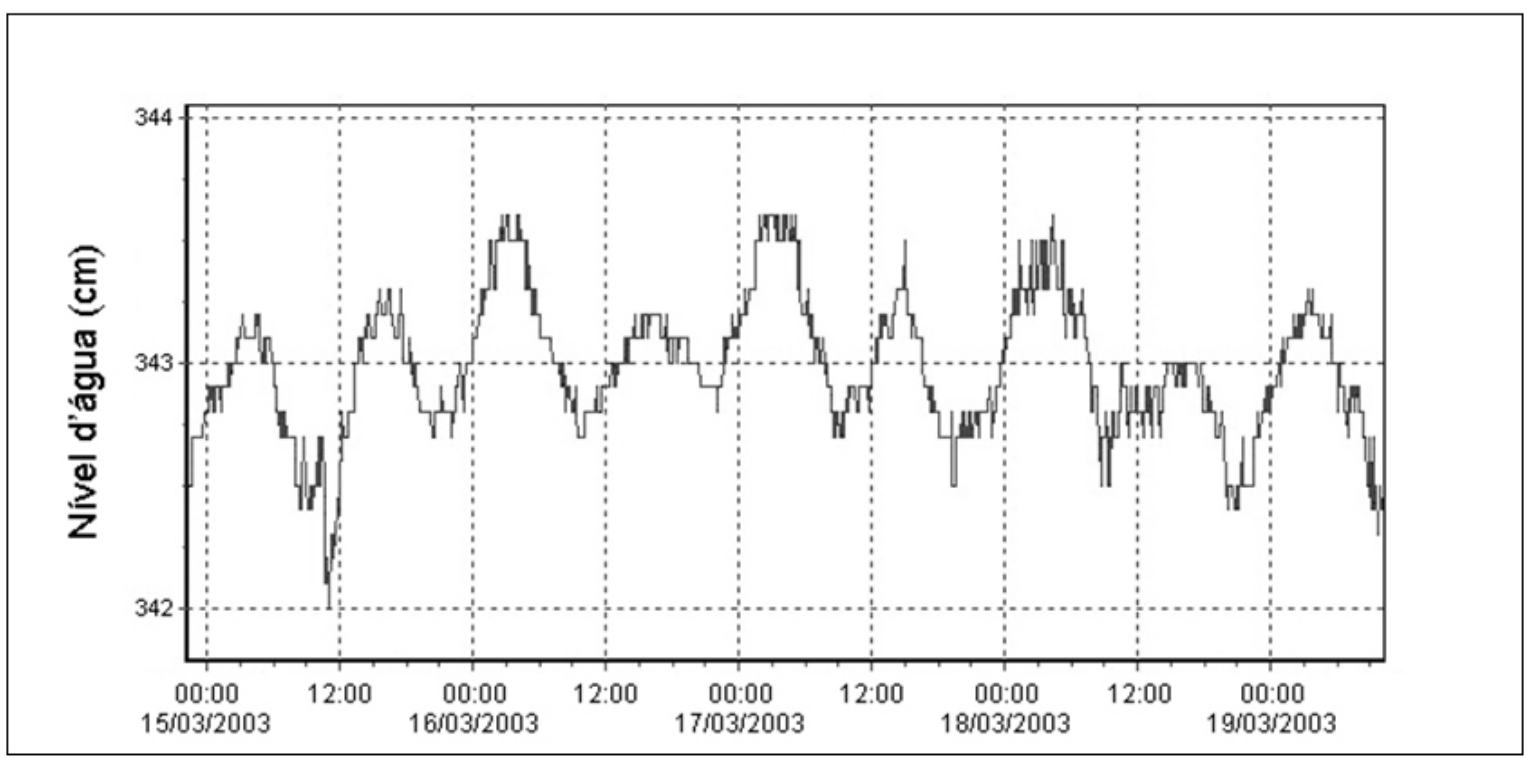

Figura 2 - Efeito da Maré Terrestre registrado no monitoramento de nível d'água. Observam-se dois ciclos diários, com diferentes amplitudes, sendo o maior ao redor das 15:00h e o menor próximo das 4:00h.

Figure 2 -Earth Tide effect recorded in water level monitoring time series. There are two daily cycles with different amplitudes, the larger around 3:00pm and the smaller at approximately 4:00am.

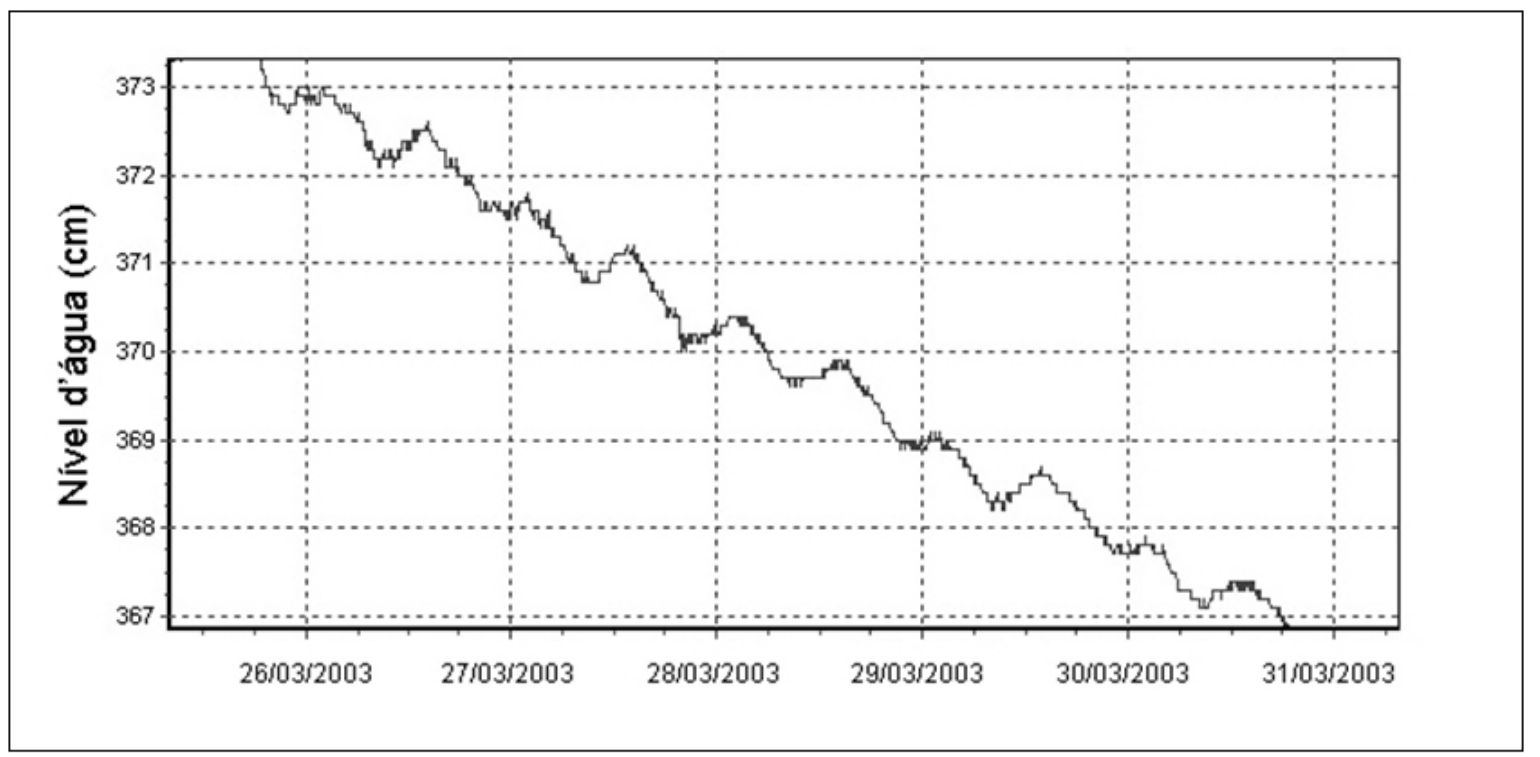

Figura 3 - Efeito da Maré Terrestre, durante o período de recessão do nível d'água.

Figure 3 - Earth Tide effect occurring at water-table recession period.

Apesar da amplitude bastante pequena (cerca de $5 \mathrm{~mm}$ ), devido à característica livre do aqüífero Rio Claro, foi possível registrar os ciclos da maré terrestre na variação de nível d'água, graças à sensibilidade dos instrumentos utilizados. O gráfico da série temporal com dados amostrados a cada cinco minutos (Figura 2), mostra a ocorrência de dois ciclos por dia, sendo o de maior amplitude registrado ao redor das $15: 00 \mathrm{hs}$ e $16: 00 \mathrm{hs}$ e o menor durante a madrugada, por volta das $3: 00 \mathrm{hs}$ e 4:00hs.

Esse fenômeno é melhor observado nas épocas em que o nível d'água está estável, ou seja, durante os períodos em que atinge um valor máximo. Durante a recessão e a recarga (nesta última, principalmente), a variação sazonal tende a suavizar essas pequenas oscilações, como mostrado na Figura 3 (trecho tomado durante o início da recessão do nível d'água).

\section{OSCILAÇÕES DE BAIXA FREQÜÊNCIA - CICLOS SAZONAIS}

De acordo com Todd (1959), ciclos sazonais ou seculares são aqueles que têm duração de alguns anos ou mais. Na Figura 4, é possível observar claramente a variação sazonal do nível d'água, resultante das variações pluviométricas anuais, e o incremento no valor dos máximos nos primeiros 
anos (2002 a 2004), caindo em 2005. Durante os três primeiros anos, a amplitude da variação do nível d'água (vale ao cume) ficou em torno de 250 a 300 $\mathrm{cm}$, diminuindo em 2005 para menos de $150 \mathrm{~cm}$. Nota-se que os trechos da curva correspondentes à recarga do poço apresentam elevada inclinação positiva. Os trechos de recessão, por sua vez, têm uma inclinação negativa e menos acentuada, de duração mais longa, cujo decaimento segue uma função exponencial.

Esse conjunto de características é muito similar àquelas vistas em hidrógrafas de rios, como o exemplo da Figura 5, que mostra a hidrógrafa anual do rio Lualaba, localizado na África Central. Observa-se, para a curva de recessão do rio, o mesmo comportamento exponencial da variação do nível d'água da Figura 4.

Como a hidrógrafa registra o fluxo de escoamento basal para a drenagem superficial, é natural que esse padrão descreva a variação do nível d'água do poço durante os períodos recessivos. A diferença marcante entre o gráfico da hidrógrafa do rio e o do nível d'água está na forma com que os períodos chuvosos são representados. Na hidrógrafa, eles são mais evidentes, pois ocorre uma mudança imediata na vazão do rio. No aqüífero, o armazenamento e a passagem da água pela zona não-saturada acabam por somar os eventos de chuva, suavizando essas flutuações de forma a exibir um incremento contínuo e praticamente constante durante a época de recarga.

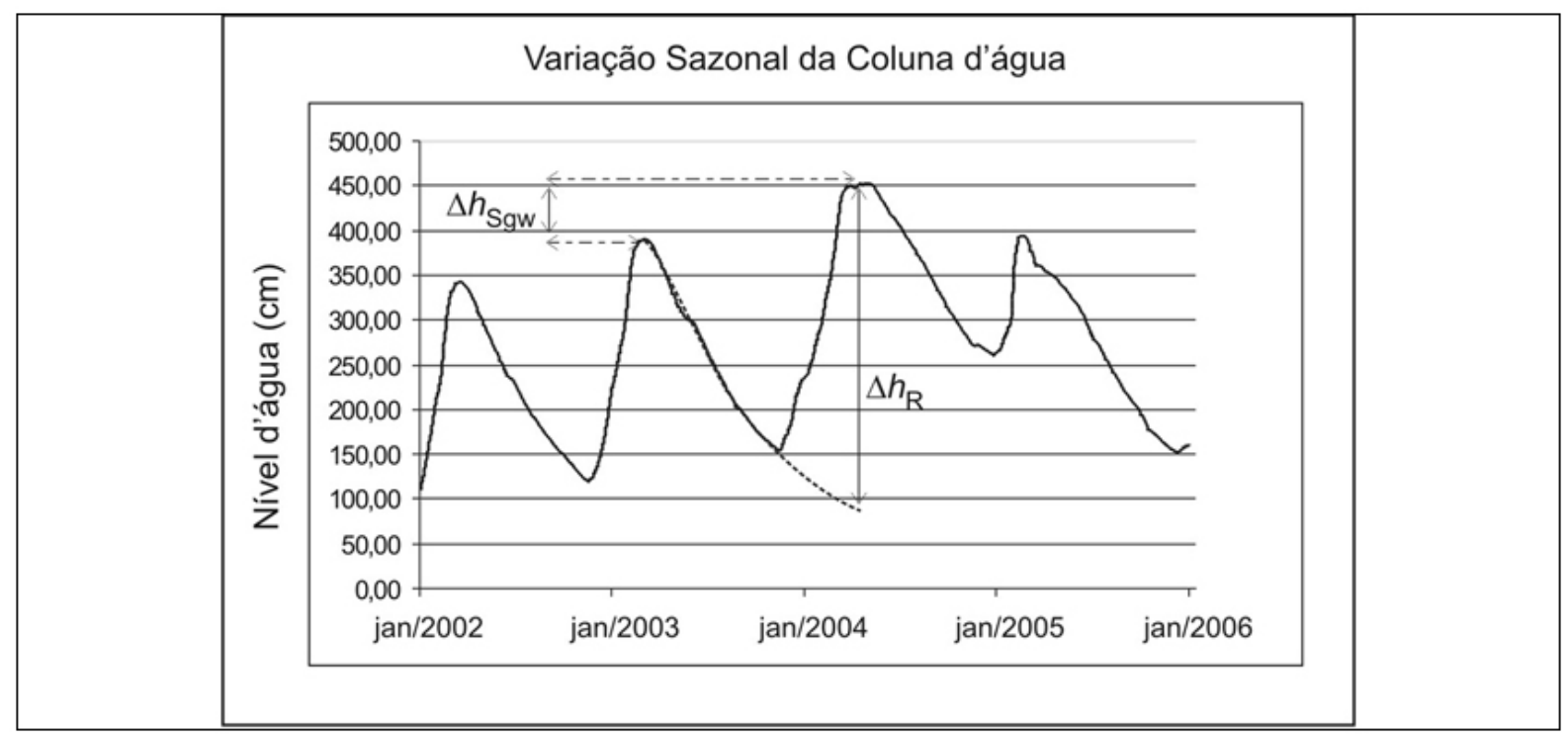

Figura 4 - Gráfico da variação sazonal do nível d'água obtido com a concatenação dos dados de monitoramento automatizado efetuado nos poços mencionados, perfurados numa porçao do Aquífero Rio Claro. A linha pontilhada indica a extrapolação das curvas de recessão segundo um ajuste exponencial, para estimativa da recarga $\mathrm{R}$. As linhas tracejadas mostram a diferença de nível d'água tomada entre dois máximos, para o cálculo da variação no armazenamento $\Delta \mathrm{S}^{\mathrm{gw}}$. Figure 4 - Water level seasonal variation plot obtained by merged data from automated monitoring wells in a portion of Rio Claro Aquifer. The dotted line represents recession curve extrapolation following an exponential adjust for recharge estimation $R$. Dashed lines indicate the difference between two water level maximum peaks used to calculate subsurface storage variation $\Delta S^{\mathrm{gw}}$.

\section{CÁLCULO DA RECARGA ANUAL NO AQÜÍFERO RIO CLARO}

Nesse trabalho foi utilizado o método WTF (water-table fluctuation) de variação do lençol freático. Trata-se de um método físico de monitoramento da zona saturada, conforme classificação de Scanlon et al. (2002), para estimar o valor da recarga total e da variação do armazenamento em subsuperfície. Este método foi aplicado em uma porção do aqüífero Rio Claro, mais precisamente na zona de recarga situada no campus Bela Vista da Unesp.-

Para o cálculo da recarga total anual, efetuou-se primeiramente a extrapolação da curva de recessão, por meio do ajuste de uma curva exponencial, tomando-se dois pontos: o valor máximo do nível d'água de cada ano como ponto inicial e o ponto mínimo seguinte, conforme mostrado na Figura 4. Essa curva é então extrapolada até a posição do máximo do ano seguinte, tomando-se a diferença $\left(\Delta h_{R}\right)$ entre esse máximo e o valor da curva extrapolada nessa posição. 


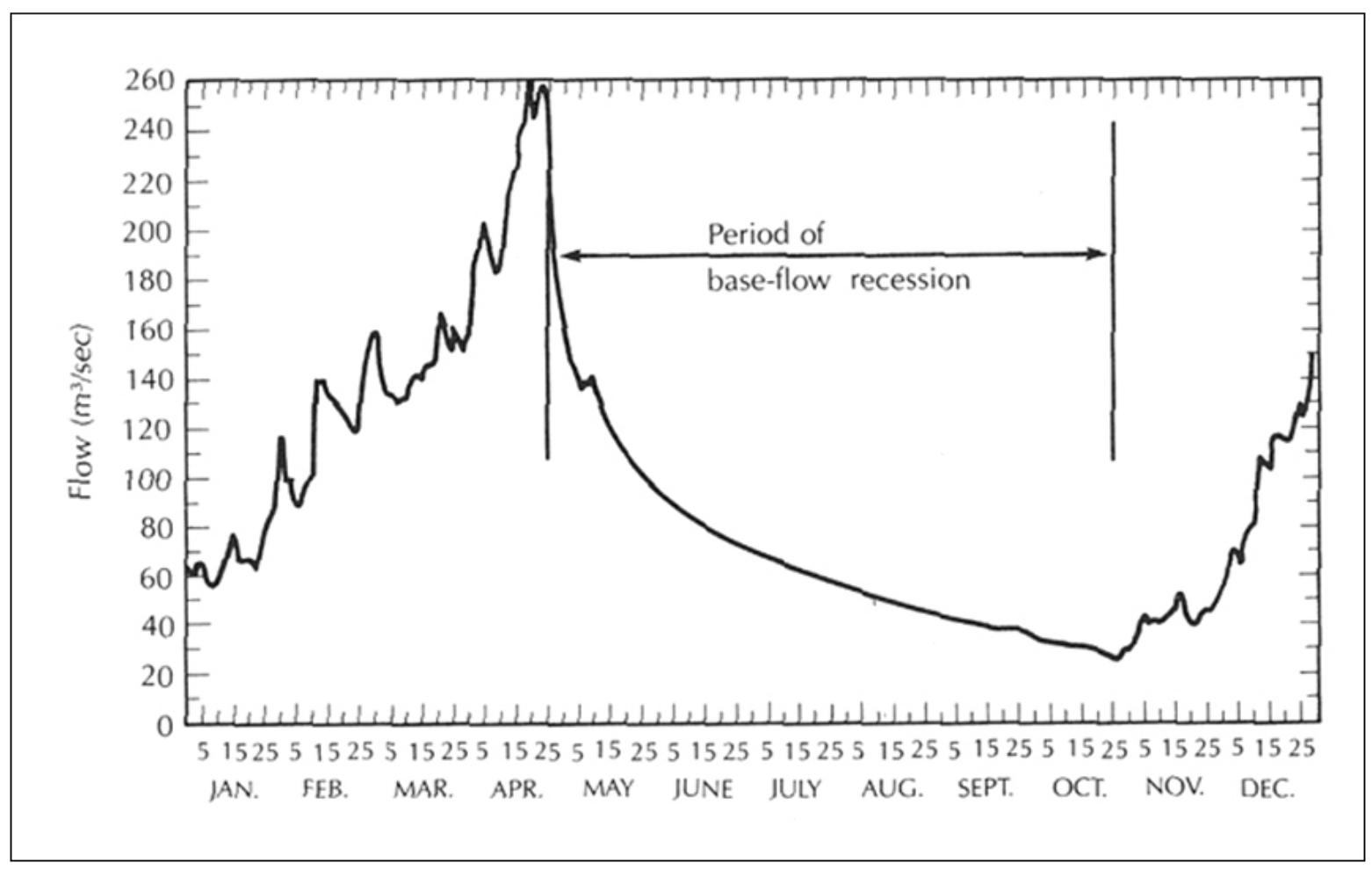

Figura 5 - Exemplo de hidrógrafa anual típica. Destaque para o trecho de recessão durante a estação de seca, com comportamento exponencial muito similar ao que ocorre no nível d'água do poço mostrado na Figura 4. Rio Lualaba, África Central (WISLER e BRATER, 1959, apud FETTER, 1994).

Figure 5 -Example of typical annual hydrograph. The period of base-flow recession display an exponential behavior very similar to the water-table variation illustrated in Figure 4. Lualaba River, Central Africa (WISLER e BRATER, 1959, apud FETTER, 1994).

O valor da recarga total $R$ é estimado utilizandose esse $\Delta h_{R}$ e o valor da porosidade específica $S_{y}$ do meio, por meio da Equação (4):

$$
R=S_{y} d h / d t=S_{y} \Delta h_{R} / \Delta t
$$

Healy e Cook (2002) fazem distinção entre a recarga total e a recarga líquida (net recharge), sendo essa última a variação do armazenamento em subsuperfície $\Delta S^{g w}$. Diferentemente da recarga total, na recarga líquida o $\Delta h$ utilizado é a diferença entre os níveis d'água de duas medidas em tempos diferentes, mostrado na Figura 4 como $\Delta h_{S g w}$.

Utilizando a equação de balanço hídrico (Equação 3), pode-se calcular a diferença entre a recarga total e a líquida, que é justamente a soma do fluxo de base, evapo-transpiração e fluxo líquido em subsuperfície. Assim,

$$
R-\Delta S^{g w}=Q^{b f}+E T^{g w}+Q_{o f f}^{g w}-Q_{o n}^{g w}
$$

na área estudada, o valor de $Q_{o n}^{g w}$ pode ser desprezado, pois a área está situada em um alto topográfico, junto ao divisor de águas, de forma que a contribuição lateral de fluxo subterrâneo é essencialmente nula.

A Tabela 1 mostra o resultado da aplicação das Equações (4) e (5) sobre os dados reunidos durante o período monitorado. O valor da porosidade específica $S_{y}$ igual a 0,17 , foi obtido a partir de ensaios de retenção de água no solo, em amostras indeformadas coletadas ao longo de poço-cacimba com $7 \mathrm{~m}$ de profundidade (KUMAYAMA, 2004; ALFARO SOTO, 2008), a poucos metros do poço IGCE-6. A variação do armazenamento $\Delta S^{g w}$ foi calculada pela diferença do nível d'água entre os máximos de um ano e seu anterior, multiplicada pela porosidade específica. A última coluna da Tabela 1 mostra o termo obtido da Equação (6), subtraindo-se $\Delta S^{g w}$ do valor de $R$, para estimar a parcela da recarga que é afetada pelos termos que representam o fluxo de base, a evapo-transpiração e o fluxo em subsuperfície.

Tabela 1 - Estimativas da Recarga Total $R$, da Variação do Armazenamento $\Delta S^{g w}, Q^{b f}$, ET e $Q^{g w}$, os três últimos termos obtidos pela diferença entre $R$ e $\Delta S^{g w}$. Valores estão expressos em $\mathrm{cm}$.

Table 1 - Estimative of Total Recharge R, Subsurface Storage $\triangle S^{\mathrm{gw}}, Q^{b f}$, ET e $Q^{\mathrm{gw}}$; the last three terms resulting from $R$ and $\Delta S^{\mathrm{gw}}$ difference. Values expressed in $\mathrm{cm}$. 


\begin{tabular}{|c|c|c|c|}
\hline Ano & $\boldsymbol{R}=\boldsymbol{S}_{v} \boldsymbol{x} \boldsymbol{\Delta} \boldsymbol{h}_{\boldsymbol{R}} / \boldsymbol{\Delta t}$ & $\boldsymbol{\Delta} \boldsymbol{S}^{g w}=\boldsymbol{S}_{v} \boldsymbol{x} \boldsymbol{\Delta} \boldsymbol{h} \boldsymbol{S}_{\mathbf{g}_{\boldsymbol{w}}} / \boldsymbol{\Delta t}$ & $\boldsymbol{Q}^{b f}+\boldsymbol{E T}^{g w}+\boldsymbol{Q}^{g w}$ \\
\hline 2002 & - & - & - \\
\hline 2003 & 53,8 & 7,99 & 45,81 \\
\hline 2004 & 63,6 & 10,68 & 52,92 \\
\hline 2005 & 29,8 & $-9,95$ & 39,75 \\
\hline
\end{tabular}

\section{CONSIDERAÇÕES FINAIS}

Com relação à estimativa da recarga, o método WTF, como qualquer outro, tem suas fontes de incertezas. Por ser dependente do valor da porosidade específica $S_{y}$, qualquer variação desse parâmetroafetaráoresultadofinal,daíaimportância de sua correta determinação. $O$ valor de 0,17 , aqui utilizado, foi escolhido por ser representativo da área monitorada. Portanto a estimativa de recarga obtida não deve ser considerada como significativa para toda a área do aqǘfero, mas sim, para a área estudada, e serve para se ter uma idéia da ordem de grandeza dos valores. Um estudo da recarga mais detalhado, de âmbito regional, levaria em consideração as heterogeneidades do aqüífero, procurando determinar os diversos valores de porosidade específica, a fim de obterse uma estimativa mais precisa da recarga para as diferentes áreas do aqüífero.

Outro ponto em que pode ocorrer incertezas é na forma como é calculada a recarga total, por meio das extrapolações de nível d'água durante os períodos de recessão. O método WTF requer que seja calculado um valor de recarga para cada aumento do nível d'água dentro do período analisado, e que são então somados para obtenção da recarga total. Na curva apresentada (Figura 4) para cada ano têm-se, de forma geral, apenas uma grande recarga seguida de uma grande recessão; durante a recarga, o incremento do nível d'água é constante, pois eventos de chuva são integrados e suavizados devido à profundidade em que se encontra o NA. Em aqüíferos mais rasos, em que o período de recarga é constituído de diversos pulsos de chuva, é necessário fazer-se a extrapolação para cada pequena recessão individual, a fim de obter-se um valor de recarga total o mais próximo possível da realidade.

A própria extrapolação é também um fator que merece a devida atenção: para o caso apresentado, em que existe apenas uma recessão de grande duração, o ajuste da curva por meio de uma equação exponencial é muito mais indicado, devido ao comportamento inerente ao fenômeno, de natureza difusiva, do que um ajuste linear. Novamente, em aqüíferos rasos que apresentam numerosos pulsos de chuva seguidos de recessões de curta duração, durante a época de recarga, a extrapolação linear pode ser uma alternativa de aplicação mais simples, dado que o trecho extrapolado está mais próximo do início da queda do nível d'água, longe do trecho assintótico da curva exponencial.

Observando-se esses detalhes, o método WTF mostra-se como uma alternativa bastante interessante, pois pode ser aplicado em uma ampla escala de tempo (da duração de um evento até todo o registro hidrológico), de área (de dezenas de $\mathrm{m}^{2}$ até centenas ou milhares de $\mathrm{m}^{2}$ ) e de magnitudes para a recarga (de alguns milímetros até dezenas de centímetros). Os dados de nível d'água que o método utiliza, a despeito da automação citada aqui, de forma geral não exigem instrumentação complexa, podendo ser conseguidos mesmo com uma amostragem realizada a intervalos de vários dias, dependendo das condições do aqüífero.

Os resultados obtidos ilustram a importância da caracterização dos fenômenos relacionados à variação do nível d'água subterrânea e como o método WTF pode ser usado de forma eficaz na estimativa da recarga por meio de dados de monitoramento de NA, contribuindo grandemente para o gerenciamento eficiente de reservas.

\section{REFERÊNCIAS}

ALFARO SOTO, M.A., CHANG H.K. Estimativa das porosidades efetiva e total em solos brasileiros. Geotecnia (Lisboa), v.1, p. 3546, 2008 .

BREDEHOEFT, J. D. Response of WellAquifer Systems to Earth Tides. Journal of Geophysical Research, v.72, n.12, p.3075-3087, Jun. 1967.

CHANG, H. K., CARNIER NETO, D.
Wellplex. INPI 00044145, 2001.

DEPARTAMENTO DE ÁGUAS E ENERGIA ELÉTRICA - DAEE. Estudo de Águas Subterrâneas, Região Administrativa 5 (Campinas), SP. São Paulo, 2V. 1981.

FETTER, C.W. Applied Hydrogeology. University of Wisconsin, Oshkosh, 3a. ed. Editora Prentice-Hall, Inc., 1994. 691p.

FREITAS, R. O.; MEZZALIRA, S.; ODA, G. 
H.; VIEIRA, P. C.; TORRES, C. C.; HACHIRO, J.; TOMINAGA, L. K.; DEHIRA, L. K.; MASSOLI, M.; AZEVEDO, A. A. B.; PRESSINOTI, M. M. N. Projeto de levantamento geológico de formações superficiais. In: Simpósio Regional de Geologia. SBG, v. 2, p. 263-277, 1979.

GERHART, J.M. Groundwater recharge and its effects on nitrate concentrations beneath a manured field site in Pennsylvania. Groundwater 24, p. 483-489, 1986.

HALL, D.W, RISSER, D.W. Effects of agricultural nutrient management on nitrogen fate and transport in Lancaster county, Pennsylvania. Water Resour Bull 29., p. 55-76, 1993.

HEALY, R.W., COOK, P.G. Using groundwater levels to estimate recharge. Hydrogeology Journal, v.10, n.1, p. 91-109, 2002.

KUMAYAMA, D. M. Calibração de um reflectômetro (TDR) para o estudo da variação do teor de umidade num perfil de solo não saturado. 74p. Trabalho de Formatura para o Curso de Geologia. Instituto de Geociências e Ciências Exatas, Universidade Estadual Paulista, Rio Claro, 2004.

LERNER, D.N, ISSAR, A.S, SIMMERS, I. A guide to understanding abd estimating natural recharge. IAH Int Contrib Hydrogeol 8. Heinz Heise, Hannover, 1990. 345p.
MEINZER, occurrence of groundwater
OLIVA, A. Estudo Hidrogeológico da Formação Rio Claro no Município de Rio ClaroSP. 71p. Dissertação (Mestrado em Geociências e Meio Ambiente) - Instituto de Geociências e Ciências Exatas, Universidade Estadual Paulista, Rio Claro, 2002.

RASMUSSEN, W.C, ANDREASEN, G.E. Hydrologic budget of the Beaverdam Creek Basin, Maryland. US Geol Surv Water-Supply Pap 1472, 1959. 106p.

ROBINSON, T. W. Earth-tides shown by fluctuations of water-levels in wells in New Mexico and Iowa. Trans. Am. Geophys. Union, v.20, p.656-666. 1939.

RUSHTON, K. Recharge from permanent water bodies. In: Simmers I (ed) Recharge of phreatic aquifers in (semi)arid areas. AA Balkema, Rotterdam, p. 215-255, 1997

SCANLON, B.R., HEALY, R.W., COOK, P.G. Choosing appropriate techniques for quantifying groundwater recharge. Hydrogeology Journal, v.10, n.1, p. 18-39, 2002.

SCHICHT, R.J., WALTON, W.C. Hydrologic budgets for three small watersheds in Illinois. Ill State Water Surv Rep Invest 40:40, 1961.

TODD, D. K. Groundwater Hidrology. Nova York : John Wiley \& Sons Inc., 1959. 320p.

VRIES, J.J. e SIMMERS, I. Groundwater recharge: an overview of processes and challenges. Hydrogeology Journal, v.10, n.1, p.5-17, 2002.

\section{AGRADECIMENTOS}

Os autores agradecem ao Laboratório de US Geol Surv Water-Supply Pap $489,1923$. $321 \mathrm{p}$.

MELO, S. M. A Formação Rio Claro e Depósitos Associados: Sedimentação Neocenozóica na Depressão Periférica Paulista. São Paulo, 144 f. (Tese de Doutoramento) - Instituto de Geociências/ USP - São Paulo, 1995.

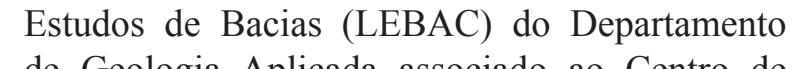
de Geologia Aplicada associado ao Centro de Estudos Ambientais da UNESP, à FUNDUNESP e CNPq (350983/1997-6), pelos apoios recebidos na realização deste trabalho. 